ADALAH : Buletin Hukum \&

Keadilan

Buletin Hukum \& Keadilan

@adalahuinjkt

\title{
Demokrasi di Era Reformasi
}

\author{
M. Makhfudz ${ }^{*}$
}

Era reformasi lahir sebagai cermin dari sikap bangsa untuk kembali pada sistem ketatanegaraan sesuai dengan konstitusi UUD 1945. Konstitusi yang dikonstruksikan sebagai bentuk kesepakatan tertinggi atau bahkan sebagai kontrak sosial bagi seluruh rakyat untuk dan dalam bernegara. Bentuk perumusannya dapat dilihat dalam Undang-Undang Dasar, atau fakta tertulis yang tidak hanya terdokumentasi dalam satu kesatuan naskah, tetapi tercatat dalam banyak naskah sejarah, seperti "Piagam Jakarta, dan sebagainya.

Dari segi isinya, konstitusi mengandung muatan nilai-nilai fundamental dan norma-norma yang dituangkan secara tertulis dan/ atau diberlakukan secara nyata dalam praktek penyelenggaraan negara. Janji itu tidak lain agar para penyelenggara kembali menjalankan negara sesuai dengan konstitusi dasar yaitu menghidupkan kembali pola berdemokrasi yang sehat sesuai ketentuan pasal 27 dan 28 UUD 1945 yaitu menghidupkan kembali terwujudnya jaminan persamaan hak bagi seluruh warga dan kebebasan mengemukakan pendapat dan kesepakatan untuk mewujudkan janji reformasi sebagaimana tercermin dalam Undang-Undang Nomor 28 Tahun 1999 tentang Penyelenggara Negara

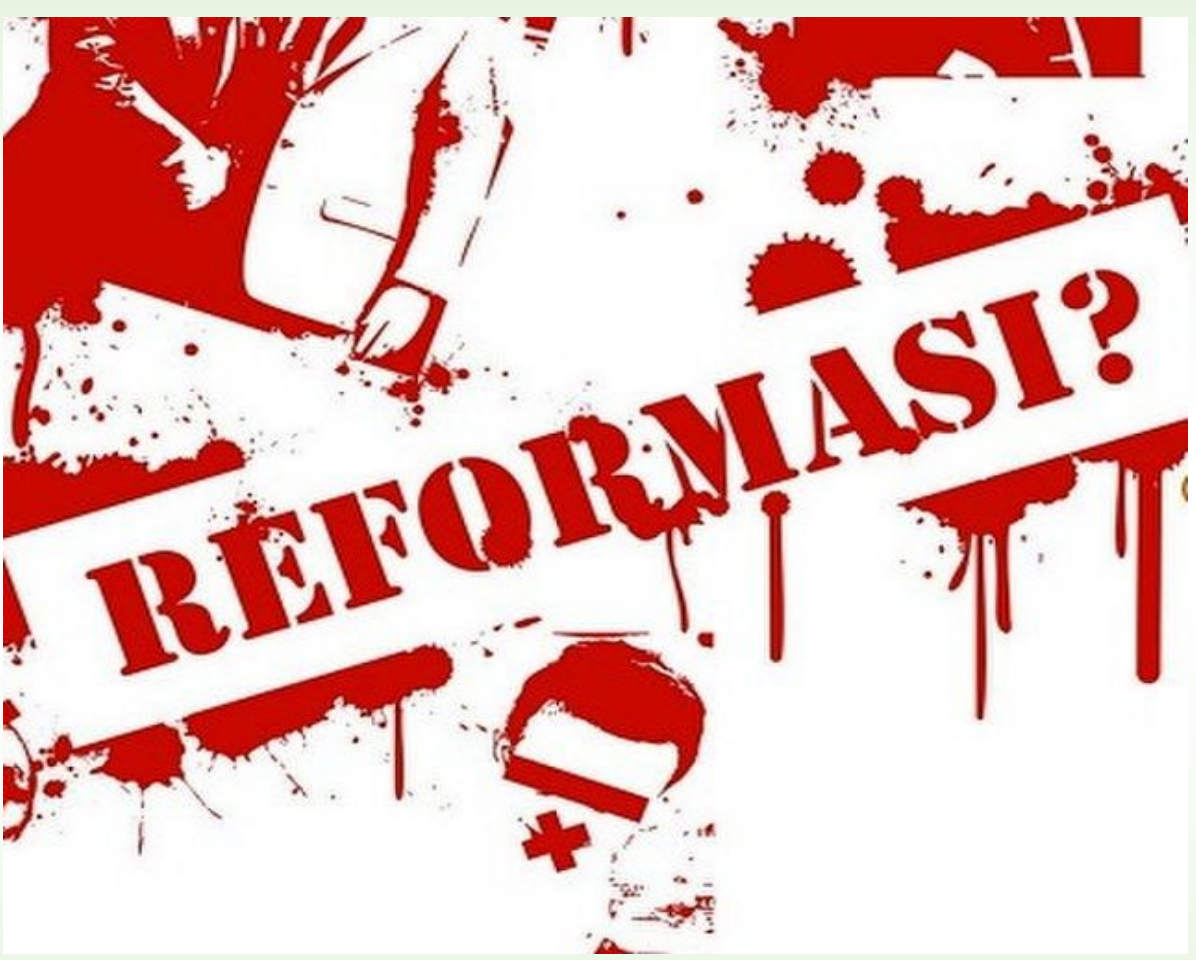

yang Bersih dari Korupsi, Kolusi dan Nepotisme. Selain dalam Demokrasi Pancasila sendiri, sistem pengorganisasian negara dilakukan oleh rakyat sendiri atau dengan persetujuan rakyat. Kebebasan individu dalam demokrasi pancasila tidak bersifat mutlak, tetapi harus diselaraskan dengan tanggung jawab sosial (Yunus, 2015: 161).

Namun dalam perjalanannya pemerintahan hasil reformasi kembali menciderai diri sendiri dengan memunculkan undangundang yang mengatur pesta demokrasi dalam memilih calon pemimpin daerah, baik provinsi maupun bupati/walikota dengan lahirnya Undang-Undang Nomor 10 Tahun 2016 tentang PILKADA. Karena dalam memilih calon pemimpin daerah terkesan memberi kesempatan pada pemimpin yang tidak bersih dengan jaminan undang-undang untuk tetap ikut serta dalam pilkada tersebut, seperti tercermin dalam pasal 7 tentang syarat calon dalam huruf $h$ berbunyi; tidak sedang dicabut hak pilihnya berdasarkan putusan pengadilan yang telah mempunyai kekuatan hukum tetap. Dari bunyi pasal ini dapat disimpulkan bakal calon Gubernur, Bupati/walikota 
yang sudah berstatus tersangka masih dijamin tetap ikut serta dalam pemilihan umum kepala daerah. Hal ini sungguh bertentangan dengan isi kontrak sosial tertinggi dalam konstitusi yang dalam janji reformasi yang menginginkan terwujudnya pemerintahan bersih dari KKN (Fauzan, 2012: 452). Saat ini, masih banyak bupati yang berstatus tersangka masih duduk sebagai penyelenggara pemerintah, seperti pada bupati di Jawa Barat dan Lampung.

Demikian juga lembaga penyelenggara Pilkada juga tidak mampu menjalankan konstitusi sesuai dengan nilai-nilai fundamental yang didalamnya termasuk nilai etik bukan sekedar norma hukum saja. Sehingga seharusnya juga melalui uji etik yang termaktub dalam pasal 7 huruf i berbunyi; tidak pernah melakukan perbuatan tercela. Dari bunyi pasal ini seharusnya dapat dilakukan seleksi terhadapnya, termasuk melakukan perbuatan berupa pernyataan yang menyinggung kepercayaan agama dari warga negara. Pernyataan menyinggung agama warga negara termasuk pelanggaran etika, karena secara nyata menimbulkan kemarahan

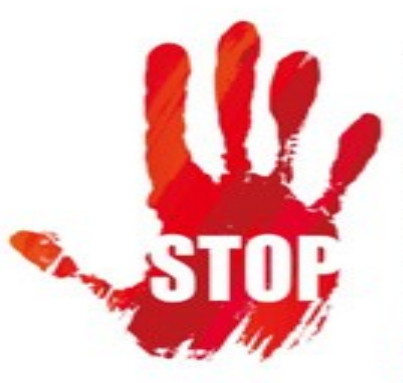

pemerintahan daerah yang tidak amanah dan tidak bersih. Sebagaimana dalam temuan KPK belum lama ini yaitu tangkap tangan terhadap seorang Bupati di Klaten Jawa Tengah dalam kasus gratifikasi kejahatan jual beli jabatan yang terjadi di lembaganya. Sungguh miris dilakukan oleh Bupati terhadap bawahannya. Bahkan lebih luas temuan KPK tidak hanya di Klaten saja, tetapi praktek Kolusi dan Nepotisme banyak ditemukan terjadi di beberapa kota.

Kesimpulannya, kini pemerintahan reformasi sudah tidak layak disebut reformis lagi karena sudah tidak konsisten dengan janji semula. Para penyelenggara negara juga tidak komitmen dengan isi konstitusi yang berisi nilai-nilai fundamental, karena konstitusi memuat berupa terkumpulnya sebagian umat muslim sampai jutaan jumlahnya di Monas. Pernyataan tersebut seyogyanya masuk dalam pelanggaran etik berat yang berakibat dicabutnya hak pilih.

Namun kenyataannya, penyelenggara pemilu baik Komisi Pemilihan Umum (KPU) maupun Badan Pengawas Pemilu (Bawaslu) tidak memahami ketentuan yang berlaku, karena pada hakikatnya berlakunya hukum memang sudah bernuansa politik. Sehingga terus menimbulkan gejolak massa yang terus menerus menodai rasa keadilan. Apabila ditunjukkan sikap akan jalankan konsensus awal pada janji luhur reformasi, seyogyanya dapat disepakati oleh pembentuk undangundang untuk membentuk rumusan undang-undang yang mendukung terwujudnya pemerintahan yang bersih, seperti dicontohkan dalam Undang-Undang Nomor 30 Tahun 2002 tentang KPK, sehingga calon yang berstatus tersangka dapat dinyatakan gugur.

Ketentuan Undang-Undang Nomor 10 Tahun 2016 dalam memilih calon pemimpin daerah yang mengemban amanat warga seharusnya lebih ketat dalam menghindari praktek penyelenggaraan

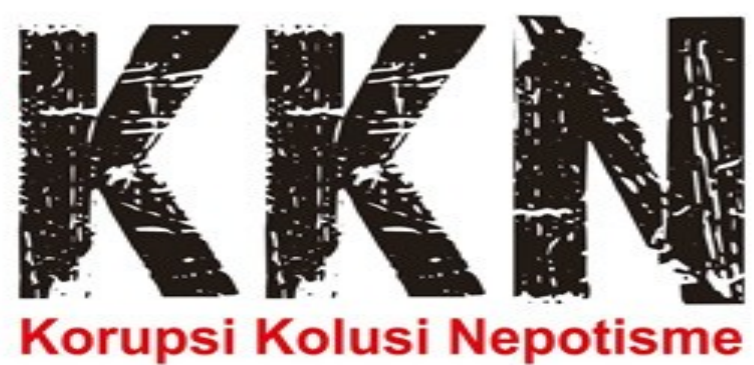

kandungan nilai dan norma yang mengatur peri kehidupan politik bernegara, serta dinamika kehidupan masyarakat dan mekanisme perekonomian negara. Sehingga lingkup konstitusi meliputi juga konstitusi sosial atau "social constitusion", sebagaimana nampak pada pasal 33 dan 34 UUD 1945 atau disebut dengan istilah "Welfare constitusion." []

\section{Pustaka Acuan:}

*Penulis adalah Dosen Fakultas Hukum Universitas Tama Jagakarsa Jakarta, sekaligus anggota Asosiasi Dosen Indonesia (ADI).

Yunus, Nur Rohim, "Aktualisasi Demokrasi Pancasila dalam Kehidupan Berbangsa dan Bernegara" dalam SOSIO DIDAKTIKA: Social Science Education Journal, Vol. 2 Nomor 2, (2015).

Fauzan, Muhammad, Bahtaruddin, Hikmah Nuraini, "Implementasi Pemerintahan Yang Bersih Dalam Kerangka Rencana Aksi Daerah Pemberantasan Korupsi (RAD-PK) (Studi Di Kabupaten Pemalang)," Jurnal Dinamika Hukum, Vol. 12 No. 3 Sep-

'Adalah; Buletin Hukum dan Keadilan merupakan berkala ilmiah yang diterbitkan oleh Pusat Studi Konstitusi dan Legislasi Nasional (POSKO-LEGNAS), Fakultas Syariah dan Hukum UIN Syarif Hidayatullah Jakarta.

Penasehat: Prof. Dr. H. Abdul Ghani Abdullah, SH., Prof. Dr. H. A Salman Maggalatung, SH., MH. Pemimpin Redaktur: Indra Rahmatullah, Tim Redaktur: Nurrohim Yunus, Fathuddin, Mara Sutan Rambe, Muhammad Ishar Helmi, Erwin Hikmatiar. Penyunting: Latipah, Siti Nurhalimah. Setting \& Layout: Siti Romlah 